Full Length Article

\title{
Development of stable current collectors for large area dye-sensitized solar cells
}

\author{
Ana Isabel Pereira ${ }^{\mathrm{a}}$, Jorge Martins ${ }^{\mathrm{a}}$, Carlos José Tavares ${ }^{\mathrm{b}}$, Luísa Andrade ${ }^{\mathrm{a}}$, \\ Adélio Mendes ${ }^{a, *}$ \\ ${ }^{a}$ LEPABE, Departamento de Engenharia Química, Faculdade de Engenharia, Universidade do Porto, Rua Dr. Roberto Frias, $4200-465$ Porto, Portugal \\ b Centro de Física, Universidade do Minho, Campus de Azurém, 4804-533 Guimarães, Portugal
}

\section{A R T I C L E I N F O}

\section{Article history:}

Received 24 January 2017

Received in revised form 29 May 2017

Accepted 19 June 2017

Available online 20 June 2017

\section{Keywords:}

Large area DSC

Photoelectrochemical

Sputtering

Sheet resistance

Tungsten

Indium-tin oxide

\begin{abstract}
A B S T R A C T
The substrate sheet resistance effect in a large area dye-sensitized solar cell (DSC) device is still the main factor responsible for low energy conversion efficiencies. In this work, current collectors made of metal lines were applied by magnetron sputtering on a transparent conducting glass substrate. The introduction of these metal lines enabled a decrease in the sheet resistance from $7.26 \Omega \cdot \square^{-1}$ to $2.52 \Omega \cdot \square^{-1}$, by depositing an optimized $1.0 \mu \mathrm{m}$ tungsten thick layer on the top of $1.5 \mu \mathrm{m}$ thick molybdenum lines. These Mo/W lines withstanded long-term stability when in contact with iodide/triiodide redox couple. Large area dye-sensitized solar cells with $36 \mathrm{~cm}^{2}$ of active area were assembled and the power conversion efficiency increased from $0.54 \%$ to $1.62 \%$ when ten metal lines were applied in both electrodes. As a final design, Mo/W lines were only applied onto the counter-electrode and protected with an indium-tin oxide layer; the resulting device showed a power conversion efficiency of $3.43 \%$, compared with the reference efficiency of $2.38 \%$.
\end{abstract}

(c) 2017 Elsevier B.V. All rights reserved.

\section{Introduction}

Dye-sensitized solar cells (DSCs) have attracted significant industrial interest in the last decades for the conversion of solar light into electricity, specially due to its simple manufacture process and low cost [1]. A DSC consists of two electrodes, the photoelectrode (PE) that is composed by a dye-sensitized mesoporous $\mathrm{TiO}_{2}$ film, and the counter-electrode (CE) that is made of a platinum catalyst thin layer; between them there is an electrolyte, typically containing the iodide/triiodide $\left(\mathrm{I}^{-} / \mathrm{I}_{3}{ }^{-}\right)$redox couple in a liquid solution [2]. While the highest certified power conversion efficiency (PCE) is $11.9 \%$ for a cell of $1.005 \mathrm{~cm}^{2}$ it was reported recently a lab size DSC with $14.3 \%$ [3]. At larger-scale, the record PCE value of $10.7 \%$ was reached for a mini-module of 7 cells connected in series with a total area of $26.55 \mathrm{~cm}^{2}$ and a PCE of $8.8 \%$ for a sub-module of $398.8 \mathrm{~cm}^{2}$ with 26 serial cells, both by Sharp [4]. This power conversion efficiency difference between lab and industrial scale is a major limitation for all photovoltaic technologies and in particular for DSCs.

\footnotetext{
* Corresponding author.

E-mail address: mendes@fe.up.pt (A. Mendes).
}

When large area glass substrates are used, typically coated with a transparent thin layer of fluorine doped tin oxide (FTO), the effect of ohmic resistance increases. As the active area of DSC increases, the short circuit current $\left(J_{S C}\right)$ and the fill factor $(F F)$ decreases, leading to a drop in conversion efficiency $[5,6]$. Electrochemical impedance spectroscopy studies and other dynamic characterization techniques revealed changes in the charge transport and recombination as the photoelectrode area increases. After injection into the semiconductor layer electrons face an increased transport resistance, which favors electron recombination with redox ions $\left(\mathrm{I}_{3}{ }^{-}\right)$present in the electrolyte [7,8]. Therefore, when large area DSCs are prepared, the charge collection efficiency becomes more significant when compared with smaller single cells.

Moreover, the ohmic resistance in a DSC substrate also depends on the cell geometry and it should be optimized to obtain high fill factors. Always, bearing in mind a simple cell design, to ensure the aesthetic aspect of the produced modules. Many solutions have been proposed to compel special attention to cells configuration and materials performance, namely, the use of large size submodules composed of multiple small area cells. However, due to the high number of small cells the aperture ratio (ratio between active and total area) is quite low [9]. Decreasing the internal ohmic resistance of a large area substrate in a DSC and maintaining the 
recombination rate independent of the area is crucial to guarantee high photovoltaic performance [10], but also very desirable for building integrated applications, enabling simpler architectures and for lower production costs [9].

The most obvious way for reducing the internal ohmic resistance of a DSC is by introducing current collectors such as metal colleting grids, in analogy with conventional photovoltaic cells. Though, for DSC applications, the selection of the current collector materials should be carefully studied due to the highly corrosive nature of $\mathrm{I}^{-} / \mathrm{I}_{3}{ }^{-}$redox couple and the ability of occurring charge recombination in the metal grids/electrolyte interface (dark current), responsible for a reduced cell photocurrent [10]. Materials like nickel, titanium, silver, aluminum and stainless steel have been studied on large area DSCs, but in most of cases a protection layer made of a resin or a glass-ceramic is needed, albeit leading to complex and expensive manufacturing processes [9-15]. Recently, Jihuai et al. prepared a PEDOT-Pt/Ti counter-electrode, where PEDOT-Pt was electrodeposited over a Ti-mesh. The photoelectrode consisted in a $100 \mathrm{~cm}^{2} \mathrm{Ti}$ foil substrate. The prepared devices showed higher energy conversion efficiencies for large cells (PCE $=6.69 \%$ ).

Within this work, two metals are investigated as current collectors for large area DSCs: tungsten and molybdenum. These two materials exhibit high resistance against electrolyte corrosion over a long time, suitable work functions to create an ohmic contact with $\mathrm{TiO}_{2}$ photoelectrode and good sheet resistance values $[2,16,17]$. The current collectors in the form of metal lines were prepared using different combinations of molybdenum and tungsten. First, the materials morphology was studied and characterized aiming the optimization of the deposition procedures and then the prepared conductive lines were applied on complete large area DSC devices for photovoltaic performance assessment.

\section{Experimental}

\subsection{Preparation of current collectors}

The current collectors were deposited directly on top of $8 \times 8.5 \mathrm{~cm}^{2}$ transparent conductive oxide (TCO) coated-glass, $2.2 \mathrm{~mm}$ thick and sheet resistance of $7 \Omega \square^{-1}$, from Solaronix ${ }^{\circledR}$, as shown in Fig. 1. The glass substrates were first washed as described elsewhere [18]. Then a metal mask was placed on top of the TCO glass substrate with the help of a double sided Kapton ${ }^{\circledR}$ tape.

The deposition of molybdenum and tungsten was made by magnetron sputtering (QPrep400 from Mantis Deposition ${ }^{\circledR}$ ), a type of physical vapor deposition (PVD). This method consists in bombarding the target (Mo or W, respectively) with energetic argon ions and subsequent ejection of neutral metal atoms species that condense as a growing film on the substrate. For the depositions, the following conditions were used: $10^{-4}$ Pa of base pressure; $20 \mathrm{sccm}$ of argon flow, where the argon pressure was controlled by the throttle valve; a bias potential of $-50 \mathrm{~V}$ applied to the substrate; and a substrate rotation speed of $6 \mathrm{rpm}$. A quartz crystal monitor (QCM) was used to measure the thickness of the conductive lines during depositions. The sample holder had a capacity for 9 glass substrates. The deposited metal line properties were optimized changing by the argon pressure $\left(P_{\mathrm{Ar}}\right)$ and substrate temperature $\left(T_{\text {Substrate }}\right)$.

The electrical resistance of the lines $\left(R_{\text {Line }}\right)$ was measured using a two-point probe technique with test probes placed $\sim 7 \mathrm{~cm}$ apart, being averaged on 10 sampling values. For each sample, 10 lines were deposited with a length of $77 \mathrm{~mm}$ and a width of $0.6 \mathrm{~mm}$, spaced $6 \mathrm{~mm}$ from each other. Sheet resistance measurements were performed using a four-point probe technique, following the Van der Pauw method, always for the same analyzed area.

A binocular stereo optical microscope (OPTIKA Italy) and scanning electron microscope (FEI Quanta FE-SEM) were used to characterize the morphology of conductive lines. X-ray diffraction (Bruker AXS D8 Discover) was employed to analyse the crystalline structure of the conductive lines. Inductively coupled plasma mass spectrometry (ICP-MS Thermo Scientific) characterization was performed to assess the corrosion of the lines when exposed to the redox electrolyte solution.

\subsection{Large area DSC device assembly}

For large area DSC photovoltaic performance assessment, twosized devices were prepared with $6 \times 6 \mathrm{~cm}^{2}$ and $2 \times 2 \mathrm{~cm}^{2}$ of active area; the cell assembly procedure was the same for both sizes. The photoelectrodes were prepared as described elsewhere [18]. Briefly, the glass substrates were treated with a $40 \mathrm{mM} \mathrm{TiCl}_{4}$ aqueous solution at $70^{\circ} \mathrm{C}$ for $30 \mathrm{~min}$ followed by three cycles of screen printing of $\mathrm{TiO}_{2}$ paste (Ti-Nanoxide T/SP from Solaronix ${ }^{\circledR}$ ), alternating with drying at $100{ }^{\circ} \mathrm{C}$ for $10 \mathrm{~min}$. The samples were then sintered at $500^{\circ} \mathrm{C}$ for $30 \mathrm{~min}$ and the final photoelectrode thickness was $12 \mu \mathrm{m}$. The counter-electrode glass substrates were drilled with four holes with $1 \mathrm{~mm}$ diameter each and the platinum paste (Platisol T/SP from Solaronix ${ }^{\circledR}$ ) was then screen printed and sintered at $450^{\circ} \mathrm{C}$ for $15 \mathrm{~min}$. Both electrodes were sandwiched and sealed with thermoplastic sealant with $60 \mu \mathrm{m}$ thick (Surlyn ${ }^{\circledR}$ from Solaronix ${ }^{\circledR}$ ) in a hotpress at $175^{\circ} \mathrm{C}$ for $15 \mathrm{~s}$; the final interdistance between the two glass substrates was $\sim 30 \mu \mathrm{m}$. Dye adsorption in the porous $\mathrm{TiO}_{2}$ photoelectrode was enabled by recirculation the dye solution ( $1 \mathrm{mM}$ of N719 from Solaronix ${ }^{\circledR}$ in ethanol) for $14 \mathrm{~h}$ using a peristaltic pump (Ismatec ${ }^{\circledR}$ Ecoline). The photoelectrode was then rinsed with ethanol, dried with nitrogen and the electrolyte (Iodolyte Z-150 from Solaronix ${ }^{\circledR}$ ) filled through the aforementioned holes, which were subsequently closed with Surlyn $^{\circledR}$ and glasses slides. Finally, silver paste (RS Components) was applied onto the electrical contacts. Half-cells devices of

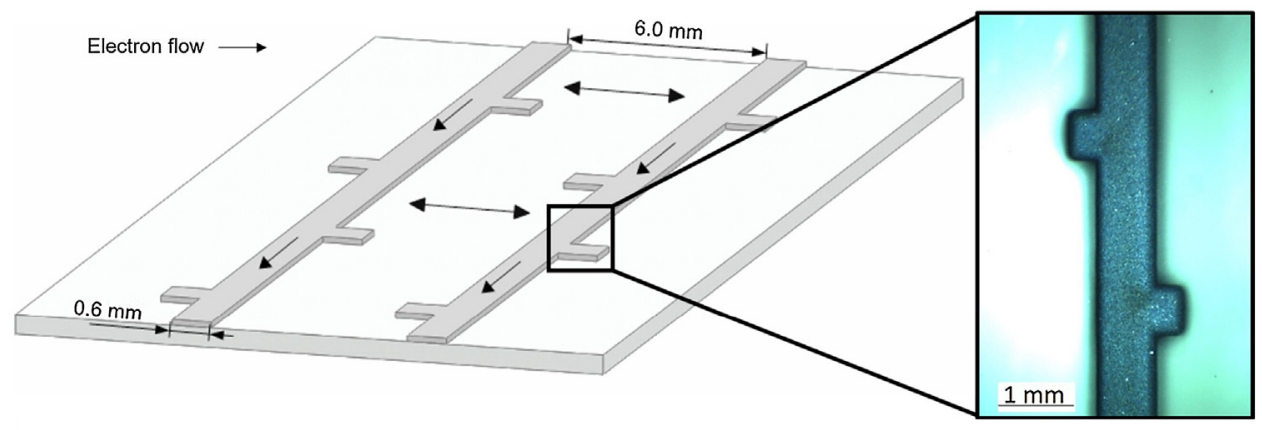

Fig. 1. Left: Current collectors design deposited on top of a TCO glass substrate (not drawn in scale). Right: Top view optical microscopy image of a current collector. 
Table 1

Operating conditions of tungsten deposition with the correspondent thickness $\left(\mathrm{d}_{\text {Line }}\right)$ and electrical resistance of the line $\left(\mathrm{R}_{\mathrm{Line}}\right)$.

\begin{tabular}{|c|c|c|c|c|c|}
\hline Sample/\# & $T_{\text {Substrate }} /{ }^{\circ} \mathrm{C}$ & $P_{\mathrm{Ar}} / \mathrm{Pa}$ & $d_{\text {Line }} / \mu \mathrm{m}$ & $R_{\text {Line }} / \Omega$ & Observations \\
\hline \#S1 & RT & 0.3 & 0.2 & 15.0 & No delamination \\
\hline \#S2 & RT & 0.3 & 0.4 & 13.8 & Lines delamination \\
\hline \#S3 & RT & 0.9 & 0.5 & 12.1 & No delamination \\
\hline \#S4 & 200 & 0.9 & 1.1 & 8.3 & No delamination \\
\hline \#S5 & 250 & 0.9 & 1.5 & 6.8 & No delamination, onset of the Kapton tape carbonization \\
\hline \#S6 & 300 & 0.9 & - & - & No line formation, mask detached \\
\hline
\end{tabular}

RT - Room temperature (never exceeding $50^{\circ} \mathrm{C}$ during deposition).

Table 2

Combinations of molybdenum (Mo) and tungsten (W) materials and the correspondent electrical resistance $\left(\mathrm{R}_{\mathrm{Line}}\right)$.

\begin{tabular}{|c|c|c|c|}
\hline Sample/\# & Materials combinations/ $\mu \mathrm{m}$ & $R_{\text {Line }} / \Omega$ & Observations \\
\hline 1\#1.5Mo & $1.5 \mu \mathrm{m}$ Mo & 4.9 & Good adhesion, no delamination \\
\hline 2\#1.0W & $1.0 \mu \mathrm{m} \mathrm{W}$ & 8.3 & Poor adhesion, no delamination \\
\hline 3\#1.5W & $1.5 \mu \mathrm{mW}$ & 6.8 & Poor adhesion, some delamination \\
\hline 4\#1.5Mo1.0W & $1.5 \mu \mathrm{m} \mathrm{Mo}+1.0 \mu \mathrm{mW}$ & 4.2 & Good adhesion, no delamination \\
\hline 5\#1.5Mo1.3W & $1.5 \mu \mathrm{m} \mathrm{Mo}+1.3 \mu \mathrm{mW}$ & 3.6 & Good adhesion, some delamination \\
\hline
\end{tabular}

$2 \times 2 \mathrm{~cm}^{2}$ were also prepared to characterize the counter-electrode, as described elsewhere [19].

\subsection{Device characterization}

$I-V$ characteristics were obtained using an electrochemical station (Autolab, PGSTAT302N). The cells were front illuminated using a solar simulator (Newport, USA) calibrated using a single crystal Si photodiode (Newport, USA); 1-sun incident radiation was used, equivalent to $1000 \mathrm{~W} \mathrm{~m}^{-2}$. Electrochemical impedance spectroscopy (EIS) measurements were performed in the dark within a frequency range from $100 \mathrm{kHz}$ to $0.05 \mathrm{~Hz}$, with an AC modulation of $10 \mathrm{mV}$; commercial software ZView ${ }^{\circledR}$ (Scribner Associates Inc.) was used.

\section{Results and discussion}

\subsection{Mo/W lines deposition}

Deposition of tungsten films and their characterization have been extensively reported in the literature. The properties of the film strongly depend on the deposition process as well as on the purity [20-23]. The tungsten deposition parameters were optimized to maximize the adhesion of $\mathrm{W}$ lines to the TCO layer and to minimize $R_{\text {Line }}$. It was observed that the operating conditions that mostly affect the lines properties were $T_{\text {Substrate }}$ and $P_{\text {Ar }}$ during the deposition. Table 1 shows different operating conditions tested for the deposition of $\mathrm{W}$ lines.

As expected, increasing the thickness of the tungsten lines favors the decrease of $R_{\text {Line }}$, however the film adhesion (delamination) is affected mainly due to residual stress formed during the deposition. Delamination was minimized increasing the $P_{\mathrm{Ar}}$ from 0.3 to $0.9 \mathrm{~Pa}$, which makes the residual stress to change from compressive to tensile [24]. Moreover, increasing the substrate temperature allows growing thicker films without delamination since higher temperature induces a residual stress relaxation and concomitant decrease in $R_{\text {Line }}$. However, this temperature increase was limited by the thermal decomposition of the Kapton ${ }^{\circledR}$ tape at ca. $250^{\circ} \mathrm{C}$. From Table 1, the operating conditions of sample \#S5 gives the lowest $R_{\text {Line }}$ and the best adhesion to the TCO glass substrate, respectively $6.8 \Omega$ of $R_{\text {Line }}$ and $1.5 \mu \mathrm{m}$ thick. Since thicker tungsten lines are difficult to obtain, it was assessed a different metal line configuration aiming to decrease further the electrical resistance; a bilayer configuration of molybdenum and tungsten (deposited using the optimized parameters in Table 1) was then tested - Table 2.
Comparing single molybdenum and tungsten lines with the

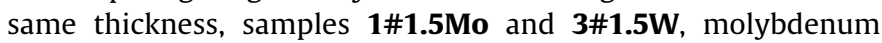
gives lower electrical resistance and better adhesion. However, as-prepared molybdenum and tungsten lines were submitted to dipping tests in the electrolyte solution over a month to evaluate their corrosion resistance. Molybdenum lines were completely dissolved, contrary to what has been reported before [16,17]. On the other hand, tungsten lines showed excellent corrosion resistance to the electrolyte. Combining the two materials in a layered metal line, where tungsten coats molybdenum, thicker and then more conductive metal lines can be obtained and corrosion resistant. Even though sample 5\#1.5Mo1.3W presents the lowest $R_{\text {Line }}$, the adhesion to the substrate was better for sample 4\#1.5Mo1.0W. Since the thickness of tungsten was lower; this limits the quality of the adhesion and consequently of the current collector. Both 4\#1.5Mo1.0W and 5\#1.5Mo1.3W samples exhibit the lowest $R_{\text {Line }}$ and for that reason these samples were applied in substrates of $36 \mathrm{~cm}^{2}$ active area - Section 3.3.

\subsection{Mo/W lines characterization}

After optimizing the current collectors deposition in terms of adhesion and electrical resistance, the combined Mo/W lines were further characterized. For that, TCO glass substrates with dimensions of $8 \times 8.5 \mathrm{~cm}^{2}$ were prepared with 10 conductive lines. Sheet resistance $\left(R_{\square}\right)$ measurements, i.e. the electrical resistance of the TCO glass substrate with coated metal lines, were performed using four-point probe measurements following the Van der Pauw method was used, where $R_{\perp}$ was measured in the perpendicular direction of the lines and $R_{=}$in the parallel direction [25] Table 3. For bare TCO glass substrate (without conductive lines), $R_{\perp}$ and $R_{=}$values are similar showing no preferential direction for the electron flow. When 10 lines with $1.0 \mu \mathrm{m}$ of tungsten were added to the TCO glass substrate, $R_{=}$decreases from $1.95 \Omega$ to $0.32 \Omega$, whereas $R_{\perp}$ increases from $1.29 \Omega$ to $2.18 \Omega$; as expected,

Table 3

Four-point probe measurements of different conductive lines on $8 \times 8.5 \mathrm{~cm}^{2}$ TCO glass substrates. $R_{\perp}$ was measured in perpendicular direction to the lines, whereas $\mathrm{R}_{\mathrm{n}}$ was measured in parallel direction to the lines.

\begin{tabular}{llll}
\hline Sample/\# & $R_{\perp} / \Omega$ & $R_{=} / \Omega$ & $R_{S} / \Omega \cdot \square^{-1}$ \\
\hline Bare TCO & 1.29 & 1.95 & 7.26 \\
2\#1.0W & 2.18 & 0.32 & 4.38 \\
4\#1.5Mo1.0W & 2.52 & 0.02 & 2.52 \\
4\#1.5Mo1.0W oxidized at $500{ }^{\circ} \mathrm{C}$ & 2.48 & 0.04 & 2.67 \\
\hline
\end{tabular}




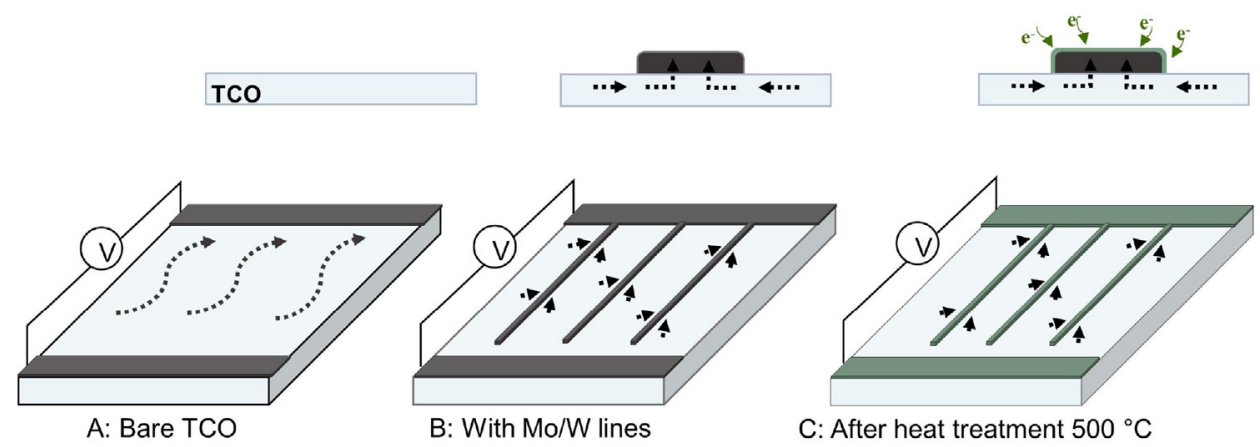

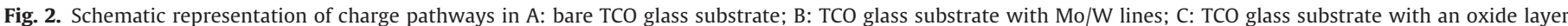
formed on the top of the Mo/W lines after heat treatment.

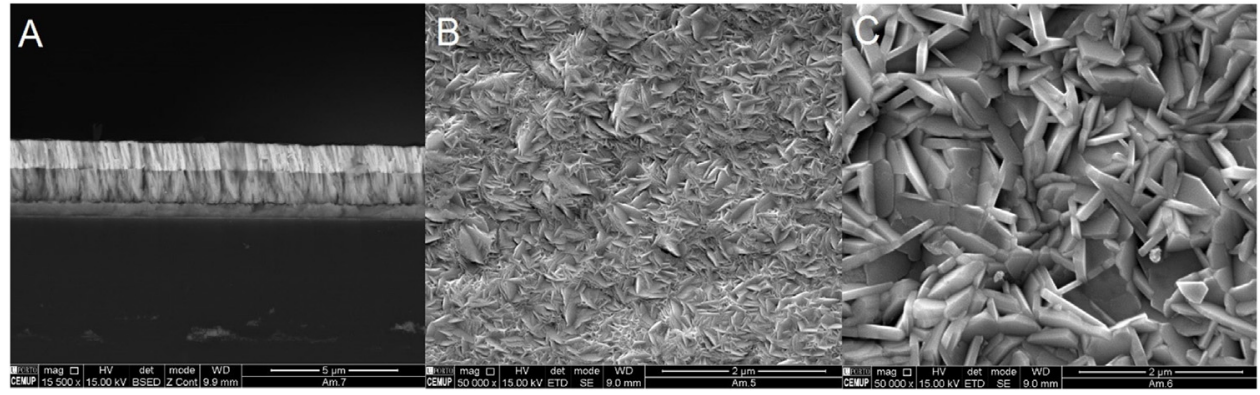

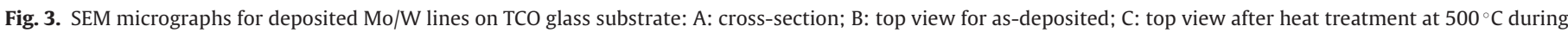
$30 \mathrm{~min}$.

the electron flow became preferential in the parallel direction of the lines. Combined Mo/W lines present an even lower $R(0.02 \Omega)$ and a highest $R_{\perp}(2.52 \Omega)$, resulting in the lowest sheet resistance obtained, $R_{\square}=2.52 \Omega \square^{-1}$. The sheet resistance stability of the combined $\mathrm{Mo} / \mathrm{W}$ lines to a thermal treatment at $500{ }^{\circ} \mathrm{C}$ during $30 \mathrm{~min}$ was assessed; this treatment simulates the $\mathrm{TiO}_{2}$ photoelectrode sintering process. This test showed that the sheet resistance after the heat treatment remains almost unchanged $\left(2.67 \Omega \square^{-1}\right)$.

Fig. 2 illustrates the electron pathways when an electrical field is applied across the substrates. For a bare TCO glass substrate electron transport is only carried through the film - Fig. 2A. Adding conductive lines, a new electric pathway emerges: electrons converge to the conductive lines from the sides, as shown by the four-point probe measurements - Fig. $2 \mathrm{~B}$ and $\mathrm{C}$. The top surface area of the conductive metal lines can be conductive - Fig. 2B - or non-conductive - Fig. $2 \mathrm{C}$, as it happens after annealing the substrate and metal oxide is formed. However, since the top metal surface area is small compared to the whole substrate area, there are no significant differences between these two cases when inserted in a DSC device, the electrical transport in TCO should remain.

The morphology of the conductive lines was analyzed by scanning electron microscopy (SEM) - Fig. 3. A SEM image of the Mo/W line cross-section is presented, Fig. $3 \mathrm{~A}$, revealing a good adhesion between the TCO glass substrate. Also, the morphology shows a compact structure, crucial to obtain low electrical resistance [26]. Fig. 3B shows the top view of the as-deposited Mo/W lines. The morphology of the metal lines is affected mainly by two reasons: the TCO glass substrate roughness and the shadow effect caused by the mask used. Looking closely to the cross section image (Fig. 3A), a laminar slanted grain structure is apparent, which should result from the angle of incidence. Top view micrograph of the Mo/W lines after a heat treatment at $500{ }^{\circ} \mathrm{C}$ during $30 \mathrm{~min}$, Fig. $3 \mathrm{C}$, shows larger crystals suggesting the presence of tungsten oxide.
The chemical composition of the thermally treated tungsten lines was compared with untreated lines using X-ray diffraction. Fig. 4 shows the diffraction patterns for tungsten with no heat treatment (black line), revealing a $\alpha$-W phase with a bodycentered cubic structure and presenting characteristic diffraction peaks from the (110), (200) and (211) reflection planes. After heat treatment, it is possible to see emerging peaks that can be attributed to monoclinic tungsten trioxide $\left(\mathrm{WO}_{3}\right)$ phase. The analysis of the characteristic diffraction peaks suggests the presence of two characteristic triplets, consisting in (002), (020) and (200) reflections between $22.1-24.6^{\circ}$, and (022), (-202) and (202) reflections between $31.9-34.9^{\circ}$. However, tungsten metal continues to be the main fraction of the sample.

ICP-MS measurements were performed to analyse metal corrosion in the redox electrolyte $\left(\mathrm{I}^{-} / \mathrm{I}_{3}{ }^{-}\right)$. The stability in the presence of the electrolyte of a sample with a $1.0 \mu \mathrm{m}$ thick tungsten line (Sample 2\#1.0W) and a sample with composite Mo/W lines (Sample 4\#1.5Mo1.0W) was assessed; molybdenum lines proved to be unstable in the presence of the electrolyte - see Section 3.1. Table 4 shows the concentration of dissolved metals after 7 and 37 days of dipping time. Tungsten lines did not corrode even after 37 days; ICP-MS measurements showed values of dissolved tungsten in the electrolyte below the detection limit of the equipment. Concerning the sample with a Mo/W line, the ICP-MS measurements showed a concentration of $0.6 \mathrm{mg} \mathrm{L}^{-1}$ of dissolved molybdenum after 7 days, maintaining the same value after 37 days. This provides evidence

Table 4

ICP-MS analysis of $\mathrm{I}^{-} / \mathrm{I}_{3}{ }^{-}$redox electrolyte after dipping of conductive lines during 7 and 37 days.

\begin{tabular}{llll}
\hline Sample & Element & After 7 days $/ \mathrm{mg} \mathrm{L}^{-1}$ & After 37 days $/ \mathrm{mg} \mathrm{L}^{-1}$ \\
\hline 2\#1.0W & W & $<0.2$ & $<0.2$ \\
4\#1.5Mo1.0W & Mo & 0.6 & 0.6 \\
\hline
\end{tabular}




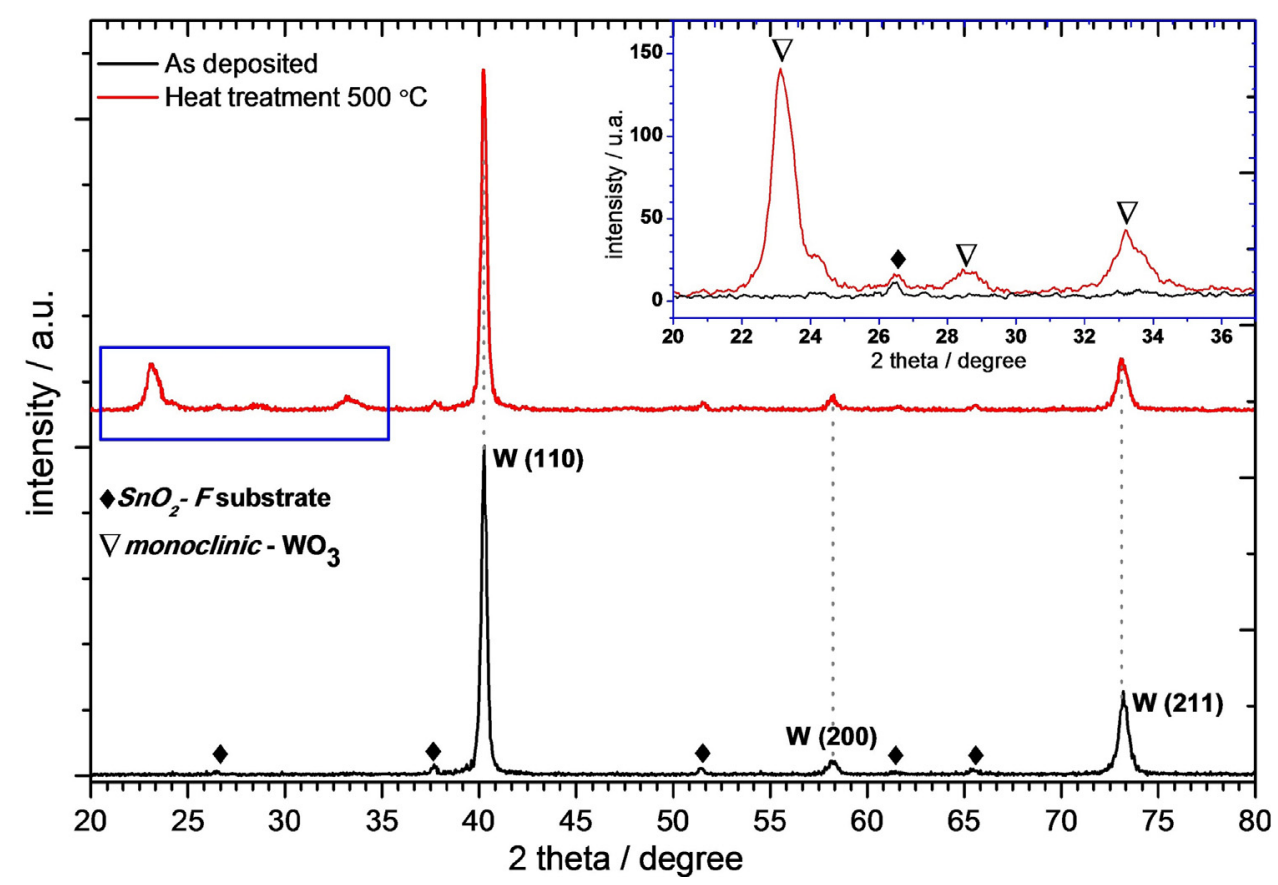

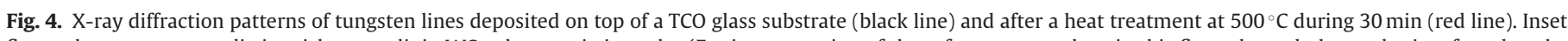

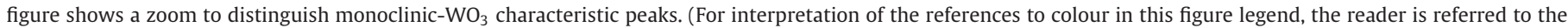
web version of this article.)

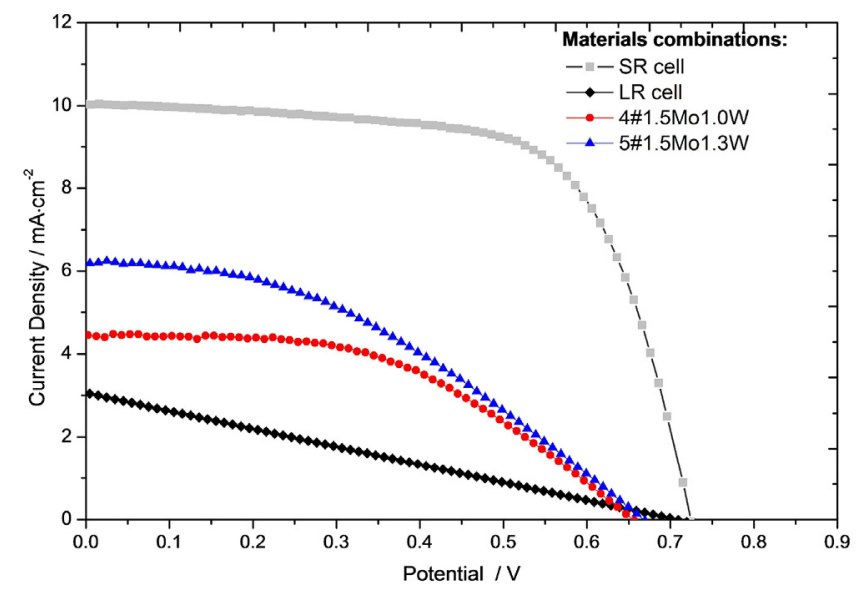

Fig. 5. I-V characteristics for small (SR) and large (LR) DSC reference cells without conductive lines and DSC devices with different combinations of Mo/W lines.

Table 5

I-V parameters for small (SR) and large (LR) DSC reference cells without conductive lines and DSC devices with different combinations Mo/W lines.

\begin{tabular}{llllll}
\hline Device & Active area $/ \mathrm{cm}^{2}$ & $V_{O C} / \mathrm{V}$ & $J_{S C} / \mathrm{mAcm}^{2}$ & $F F$ & $\eta / \%$ \\
\hline SR cell & 0.196 & 0.73 & 10.03 & 0.65 & 5.02 \\
LR cell & 36.0 & 0.70 & 3.05 & 0.25 & 0.54 \\
4\#1.5Mo1.0W & 32.4 & 0.65 & 4.45 & 0.49 & 1.42 \\
5\#1.5Mo1.3W & 32.4 & 0.66 & 6.19 & 0.39 & 1.62 \\
\hline
\end{tabular}

that the tungsten protective layer has a significant ability to protect the underlying molybdenum layer from corrosion.

\subsection{Large area DSC characterization}

A series of DSC devices were prepared incorporating the developed conductive lines in both substrate sides and characterized in terms of photovoltaic performance - Fig. 5 and Table 5.

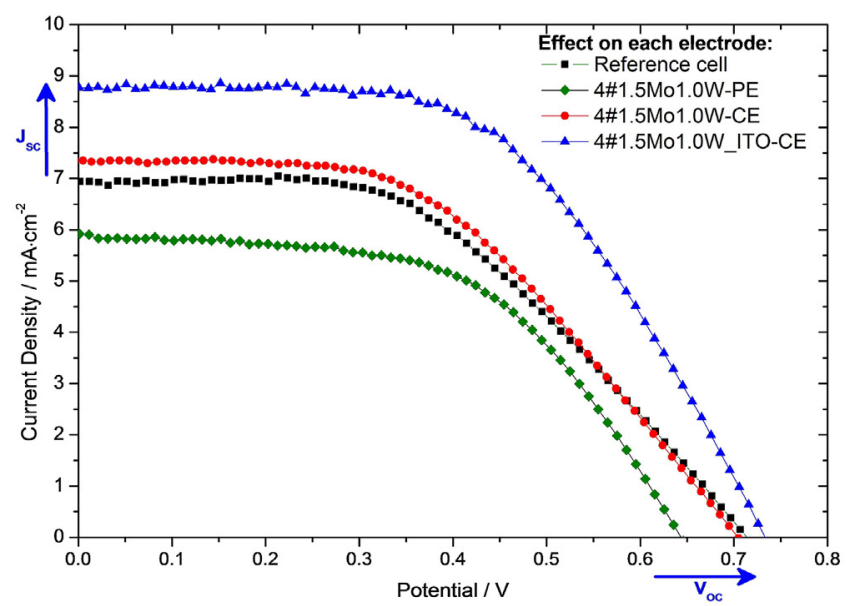

Fig. 6. I-V characteristics for a DSC with a $2 \times 2 \mathrm{~cm}^{2}$ design without lines (Reference cell) and the effect of adding Mo/W lines on the photo and on the counter-electrode side.

Two DSC reference cells were considered: a small circular (SR cell) of $0.196 \mathrm{~cm}^{2}$ and a large one with $6 \times 6 \mathrm{~cm}^{2}$ without conductive lines (LR cell); when Mo/W lines are applied the active area decreases from $36 \mathrm{~cm}^{2}$ to $32.4 \mathrm{~cm}^{2}$ due to the shadow caused by the lines. As expected, it was observed a significant difference on the power conversion efficiency between the two cells. Concerning the devices incorporating Mo/W lines, with 4\#1.5Mo1.0W and 5\#1.5Mo1.3W devices, it was observed a power conversion efficiency enhancement from $0.54 \%$ (LR cell) to $1.42 \%(\mathbf{4 \# 1 . 5 M o 1 . 0 W})$ and further increased to $1.62 \%(\mathbf{5 \# 1 . 5 M o 1 . 3 W})$; the photovoltaic performance enhancement occurred mainly due to $J_{S C}$ and FF improvement. The current density increases approximately proportionally to the sheet resistance decrease.

The effect of conductive lines on each electrode (photo and counter-electrodes) was studied for a device with $2 \times 2 \mathrm{~cm}^{2}$ incorporating 4\#1.5Mo1.0W metal lines. Fig. 6 shows that adding 

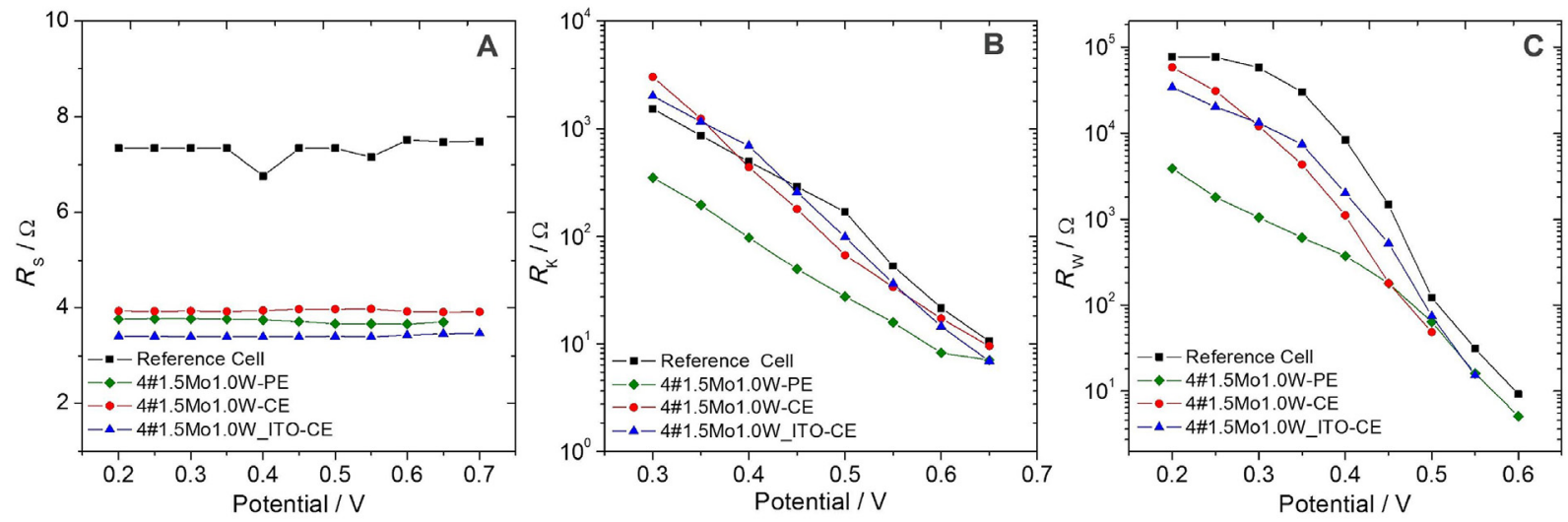

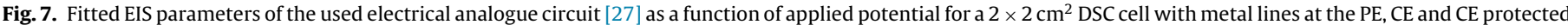
with ITO layer. A: series resistance $\left(R_{S}\right)$ B: recombination resistance $\left(R_{k}\right)$ and C: transport resistance $\left(R_{w}\right)$.

Table 6

I-V parameters for a DSC with a $2 \times 2 \mathrm{~cm}^{2}$ design without lines (Reference cell) and the effect of adding Mo/W lines on the photo and on the counter-electrode side.

\begin{tabular}{llllll}
\hline Device & Active area $/ \mathrm{cm}^{2}$ & $V_{O C} / \mathrm{V}$ & $J_{S C} / \mathrm{mAcm}^{2}$ & $F F$ & $\eta / \%$ \\
\hline Reference cell & 4.0 & 0.71 & 6.93 & 0.48 & 2.38 \\
4\#1.5Mo1.0W-PE & 3.5 & 0.64 & 5.92 & 0.55 & 2.09 \\
4\#1.5Mo1.0W-CE & 4.0 & 0.70 & 7.35 & 0.49 & 2.52 \\
4\#1.5Mo1.0W_ITO-CE & 4.0 & 0.73 & 8.78 & 0.55 & 3.53 \\
\hline
\end{tabular}

conductive lines to the photoelectrode lowers the conversion efficiency from $2.38 \%$ to $2.09 \%$. Conversely, while adding the same lines to the counter-electrode enhances the conversion efficiency to $2.52 \%$. Table 6 shows that the applied Mo/W lines to the photoelectrode decrease both $J_{\mathrm{SC}}$ and $V_{\mathrm{OC}}$, whereas when these lines are applied to the counter-electrode $J_{\mathrm{SC}}$ increases and $V_{\mathrm{OC}}$ remains approximately constant. Furthermore, device 4\#1.5Mo1.0W_ITOCE with metal lines covered with a thin layer of indium-tin oxide (ITO) in the counter-electrode is discussed below.

The electrochemical impedance spectra obtained in the dark at applied potentials between $0.2 \mathrm{~V}$ and $0.7 \mathrm{~V}$, with steps of $0.05 \mathrm{~V}$, were fitted using a transmission line model and a simple circuit model, depending on the potential range [27]. Fig. 7 presents the resistance parameters as a function of the potential obtained from fitting the model to the Nyquist plot, where $R_{\mathrm{S}}$ is the series resistance for the transport resistance of the TCO/lines, $R_{\mathrm{k}}$ is the charge-transfer resistance related to recombination of electrons at $\mathrm{TiO}_{2}$ /electrolyte interface and $R_{\mathrm{W}}$ is the electron transport resistance in the mesoporous $\mathrm{TiO}_{2}$ photoelectrode.

Compared with reference cell (ca. $7 \Omega$ ), the series resistance decreases for all devices with Mo/W lines, where the lowest value

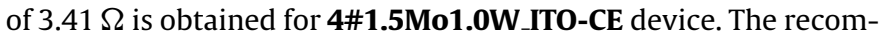
bination resistance $\left(R_{\mathrm{k}}\right)$ for 4\#1.5Mo1.0W-PE device is smaller than for the reference cell; this is in agreement with the photovoltaic performance - Fig. 7. Moreover, this same device has a lower transport resistance $\left(R_{\mathrm{W}}\right)$, indicating that using conductive lines benefits the electron transport in the photoelectrode side. For the latter device, the electron recombination effect overcomes the electron transport resistance decrease induced by the Mo/W lines. The electron recombination increase should be related to the electrolyte reduction at the metal lines $[28,29]$. On the other hand, 4\#1.5Mo1.0W-CE device displays $R_{\mathrm{k}}$ and $R_{\mathrm{W}}$ values in line with the reference cell.

Since the use of collecting metal lines seems to increase the recombination rate, it was considered the use of a protective layer of ITO applied on the counter-electrode over the metal lines. ITO was selected since it is widely used on photovoltaic devices as

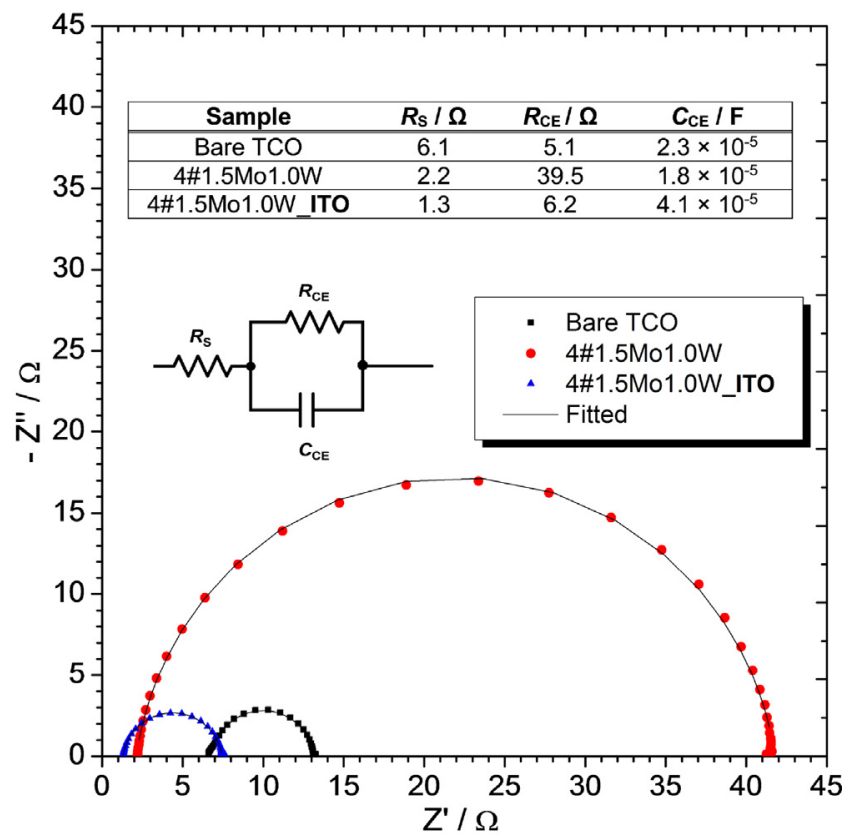

Fig. 8. Half-cells assembled with counter-electrodes studied in this work. EIS spectra with Nyquist plots, for different substrates applied on the counter-electrodes in large-area $2 \times 2 \mathrm{~cm}^{2}$ DSC devices.

DSCs due to its low sheet resistance and high transmittance in the visible region [30,31]. However, this material is sensitive to the $\mathrm{TiCl}_{4}$ solution used to prepare the blocking layer at the photoelectrode side, preventing its use in the photoelectrode [32]. ITO layer was applied by magnetron sputtering up to a thickness of ca. $40 \mathrm{~nm}$ (4\#1.5Mo1.0W_ITO-CE device). Sheet resistance measurements of this sample showed $2.63 \Omega \square^{-1}$, a value similar to that obtained for the best samples listed in Table 3 . The results in Fig. 7 and Table 6 indicates that the use of an ITO protective layer results in a substantial energy conversion efficiency increase, from $2.38 \%$ to $3.53 \%$. Since all parameters controlling the efficiency and related to the photoelectrode are similar to device 4\#1.5Mo1.0WCE, the enhanced photovoltaic performance should be assigned to the counter-electrode as discussed below.

Half-cells of $2 \times 2 \mathrm{~cm}^{2}$ were assembled in order to better understand the phenomena taking place in the counter-electrode side. The influence of adding 4\#1.5Mo1.0W metal lines to a TCO glass substrate was analyzed. Also the effect of coating these lines with a ca. $40 \mathrm{~nm}$ thick ITO thin protective layer was assessed. All these 
devices were coated with a catalytic platinum layer sintered at $450^{\circ} \mathrm{C}$. Fig. 8 displays the Nyquist plots of the three half-cells at $0 \mathrm{~V}$.

A simplified Randles electrical analogue was used to fit the experimental data as described elsewhere [33]. When Mo/W lines were added to the TCO glass substrate, the series resistance $\left(R_{\mathrm{S}}\right)$ decreased from $6.1 \Omega$ to $2.2 \Omega$ but the charge-transfer resistance at the counter-electrode $\left(R_{\mathrm{CE}}\right)$ increased almost 8-fold, from $5.1 \Omega$ to $39.5 \Omega$. Although $\mathrm{Mo} / \mathrm{W}$ lines prejudices the counter-electrode performance in $R_{\mathrm{CE}}$, the device photovoltaic performance was increased due to the lower $R_{S}$. When adding the ITO protective layer $R_{\mathrm{S}}$ was further reduced to $1.3 \Omega$ and concomitantly $R_{\mathrm{CE}}$ decreased to values close to that of the reference device, hence justifying the increased photovoltaic performance from the 4\#1.5Mo1.0W_ITOCE device.

\section{Conclusions}

The present work studied the use of metal lines on TCO glass substrates for minimizing the sheet resistance in large sized dyesensitized solar cells. Though tungsten proved to be a promising metal for serving as current collector in DSCs, due to its chemical stability and high electrical conductivity, it proved to be quite difficult to sputter tungsten to the required line thickness. A bilayer collecting lines structure comprising of a bottom molybdenum layer capped with tungsten was optimized. The best performing design comprehends a $1.0 \mu \mathrm{m}$ layer of $\mathrm{W}$ that coats a $1.5 \mu \mathrm{m}$ layer of Mo. This design displays a good adhesion to the TCO layer and a lower sheet resistance. When ten metal lines were applied to $36 \mathrm{~cm}^{2}$ active area DSC, the sheet resistance decreased from $7 \Omega \square^{-1}$ to $2.52 \Omega \square^{-1}$ and the power conversion efficiency increased from $0.54 \%$ (reference device) to $1.62 \%$. When these metal lines were applied to the photoelectrode the recombination rate resistance increased substantially, resulting in low performing DSC devices. A new approach was subsequently followed by coating the metal lines at the CE with a protective ITO layer; the DSC devices prepared this way improved the energy conversion efficiency to $3.53 \%$, by far overcoming the previous performances. Half-cells confirmed that the ITO protective layer shows significantly lower charge-transfer resistance compared with the substrate with bare metal lines.

\section{Acknowledgements}

A. I. Pereira is grateful to Portuguese Foundation for Science and Technology (FCT) through the project SolarConcept (PTDC/EQUEQU/120064/2010). A. Mendes and L. Andrade acknowledge the European Commission through the Seventh Framework Programme, the Specific Programme "Ideas" of the European Research Council for research and technological development as part of an Advanced Grant under grant agreement no. 321315 (BI-DSC).

This work was also partially supported by the projects POCI-01-0145-FEDER-006939 (Laboratory for Process Engineering, Environment, Biotechnology and Energy - UID/EQU/00511/2013) funded by the European Regional Development Fund (ERDF), through COMPETE2020 - Programa Operacional Competitividade e Internacionalização (POCI) and by national funds, through FCT and by NORTE-01-0145-FEDER-000005-LEPABE-2-ECO-INNOVATION, supported by North Portugal Regional Operational Programme (NORTE 2020), under the Portugal 2020 Partnership Agreement, through the European Regional Development Fund (ERDF).

The authors are thankful to CEMUP for the SEM-EDS analysis and also to SEMAT/UM for the X-ray diffraction analysis.

\section{References}

[1] H. Ossenbrink, T. Huld, A.J. Waldau, N. Taylor, Photovoltaic electricity cost maps, in: JRC Scienctific and Policy Reports, 2013.

[2] M. Gratzel, Photoelectrochemical cells, Nature 414 (November) (2001) 338-344.

[3] K. Kakiage, Y. Aoyama, T. Yano, K. Oya, J. Fujisawa, M. Hanaya, Highly-efficient dye-sensitized solar cells with collaborative sensitization by silyl-anchor and carboxy-anchor dyes, Chem. Commun. (Camb.) 51 (2015) 15894-15897.

[4] M.A. Green, K. Emery, Y. Hishikawa, W. Warta, E.D. Dunlop, D.H. Levi, et al., Solar cell efficiency tables (version 49), Prog. Photovoltaics Res. Appl. 25 (2017) 3-13.

[5] L. Han, N. Koide, Y. Chiba, A. Islam, R. Komiya, N. Fuke, et al., Improvement of efficiency of dye-sensitized solar cells by reduction of internal resistance, Appl. Phys. Lett. 86 (2005) 213501.

[6] J. Halme, P. Vahermaa, K. Miettunen, P. Lund, Device physics of dye solar cells, Adv. Mater. 22 (September) (2010) E210-E234

[7] A. Fakharuddin, I. Ahmed, Q. Wali, Z. bin Khalidin, M.M. Yosuff, J. Rajan, Probing electron lifetime and recombination dynamics in large area dye-sensitized solar cells by electrochemical impedance spectroscopy, Micro/Nano Sci. Eng. 925 (2014) 553-558.

[8] A. Fakharuddin, P.S. Archana, Z. Kalidin, M.M. Yusoff, R. Jose, Standardization of photoelectrode area of dye-sensitized solar cells, RSC Adv. 3 (2013) 2683-2689.

[9] K. Okada, H. Matsui, T. Kawashima, T. Ezure, N. Tanabe, $100 \mathrm{~mm}$ x $100 \mathrm{~mm}$ large-sized dye sensitized solar cells, J. Photochem. Photobiol. A-Chem. 164 (2004) 193-198.

[10] Z. Lan, J.H. Wu, J.M. Lin, M.L. Huang, Bi-functional TiO2 cemented Ag grid under layer for enhancing the photovoltaic performance of a large-area dye-sensitized solar cell, Electrochim. Acta 62 (February) (2012) 313-318.

[11] G.R.A. Kumara, S. Kawasaki, P.V.V. Jayaweera, E.V.A. Premalal, S. Kaneko, Large area dye-sensitized solar cells with titanium based counter electrode, Thin Solid Films 520 (2012) 4119-4121.

[12] D.H. Yeon, K.K. Kim, N.G. Park, Y.S. Cho, Bismuth borosilicate-based thick film passivation of Ag grid for large-area dye-sensitized solar cells, J. Am. Ceram. Soc. 93 (June) (2010) 1554-1556.

[13] J. Wu, Y. Xiao, Q. Tang, G. Yue, J. Lin, M. Huang, et al., A large-area light-weight dye-sensitized solar cell based on all titanium substrates with an efficiency of 6.69\% outdoors, Adv. Mater. 24 (2012) 1884-1888.

[14] J. Chua, N. Mathews, J.R. Jennings, G. Yang, Q. Wang, S.G. Mhaisalkar, Patterned 3-dimensional metal grid electrodes as alternative electron collectors in dye-sensitized solar cells, Phys. Chem. Chem. Phys. 13 (November) (2011) 19314-19317.

[15] L. Meng, M. Wu, Y. Wang, W. Guo, C. Ma, T. Ma, et al., Effect of the compact Ti layer on the efficiency of dye-sensitized solar cells assembled using stainless steel sheets, Appl. Surf. Sci. 275 (2013) 222-226, 6/15/2013.

[16] G.J. Reynolds, T.M. Watson, G. Williams, D.A. Worsley, Corrosion resistance of metallic substrates for the fabrication dye-sensitized solar cells Photovoltaics for the 21st Century 6, vol. 33, 2011, pp. 129-138, March 21, 2011.

[17] T. Watson, G. Reynolds, D. Wragg, G. Williams, D. Worsley, Corrosion monitoring of flexible metallic substrates for dye-sensitized solar cells, Int. J. Photoenergy 2013 (2013) 8.

[18] J. Macaira, I. Mesquita, L. Andrade, A. Mendes, Role of temperature in the recombination reaction on dye-sensitized solar cells, Phys. Chem. Chem. Phys. 17 (September) (2015) 22699-22710.

[19] R. Cruz, D.A.P. Tanaka, A. Mendes, Reduced graphene oxide films as transparent counter-electrodes for dye-sensitized solar cells, Sol. Energy 86 (February) (2012) 716-724.

[20] E. Vassallo, R. Caniello, M. Canetti, D. Dellasega, M. Passoni, Microstructural characterisation of tungsten coatings deposited using plasma sputtering on $\mathrm{Si}$ substrates, Thin Solid Films 558 (2014) 189-193.

[21] B. Girault, D. Eyidi, P. Goudeau, T. Sauvage, P. Guerin, E. Le Bourhis, et al., Controlled nanostructuration of polycrystalline tungsten thin films, J. Appl. Phys. 113 (May) (2013) 174310

[22] T. Karabacak, C.R. Picu, J.J. Senkevich, G.C. Wang, T.M. Lu, Stress reduction in tungsten films using nanostructured compliant layers, J. Appl. Phys. 96 (November) (2004) 5740-5746.

[23] I.-L. Velicu, V. Tiron, C. Porosnicu, I. Burducea, N. Lupu, G. Stoian, et al., Enhanced properties of tungsten thin films deposited with a novel HiPIMS approach, Appl. Surf. Sci. (2017).

[24] Y.G. Shen, Y.W. Mai, Q.C. Zhang, D.R. McKenzie, W.D. McFall, W.E. McBride, Residual stress, microstructure, and structure of tungsten thin films deposited by magnetron sputtering, J. Appl. Phys. 87 (2000) 177

[25] L.J.v.d. Pauw, A method of measuring specific resistivity and hall effect of discs of arbitrary shape, Philips Res. Rep. 13 (1958) 1-9.

[26] S.-I. Jun, P.D. Rack, T.E. McKnight, A.V. Melechko, M.L. Simpson, Electrical and microstructural characterization of molybdenum tungsten electrodes using a combinatorial thin film sputtering technique, J. Appl. Phys. 97 (2005) 054906.

[27] F. Fabregat-Santiago, J. Bisquert, G. Garcia-Belmonte, G. Boschloo, A. Hagfeldt, Influence of electrolyte in transport and recombination in dye-sensitized solar cells studied by impedance spectroscopy, Sol. Energy Mater. Sol. Cells 87 (2005) 117-131.

[28] S. Ito, P. Liska, P. Comte, R. Charvet, P. Pechy, U. Bach, et al., Control of dark current in photoelectrochemical (TiO2/I-I3-) and dye-sensitized solar cells, Chem. Commun. (2005) 4351-4353. 
[29] H. Zheng, Y. Tachibana, K. Kalantar-Zadeh, Dye-sensitized solar cells based on WO3, Langmuir 26 (December) (2010) 19148-19152.

[30] K. Goto, T. Kawashima, N. Tanabe, Heat-resisting TCO films for PV cells, Sol. Energy Mater. Sol. Cells 90 (2006) 3251-3260.

[31] K.-S. Tseng, Y.-L. Lo, Effect of sputtering parameters on optical and electrical properties of ITO films on PET substrates, Appl. Surf. Sci. 285 (Part B) (2013) 157-166, 11/15/2013.
[32] S. Gardonio, L. Gregoratti, D. Scaini, C. Castellarin-Cudia, P. Dudin, P. Melpignano, et al., Characterization of indium tin oxide surfaces after $\mathrm{KOH}$ and $\mathrm{HCl}$ treatments, Org. Electron. 9 (2008) 253-261.

[33] A. Hauch, A. Georg, Diffusion in the electrolyte and charge-transfer reaction at the platinum electrode in dye-sensitized solar cells, Electrochim. Acta 46 (2001) 3457-3466. 